\title{
HPLC DETERMINATION OF CIPROFLOXACIN RESIDUES IN CHICKEN MEAT AND ITS PRODUCTS
}

\author{
MOHAMED KARMI \\ Department of Food Hygiene, Faculty of Veterinary Medicine, Aswan University, \\ 81528 Aswan, Egypt
}

Received: 12 March 2019; Accepted: 8 April 2019

\begin{abstract}
This study consisted of two main parts; the first part is an experimental part consisted from 55 antibiotic-free 35 -days chickens that treated with therapeutic dose $(5 \mathrm{mg} / \mathrm{kg}$ body weight) in drinking water for three successive days to study the withdrawal time and the effect of freezing and heat treatment on the drug residues. The second part is a survey consisted from 100 samples include fresh, frozen chickens, chicken burgers and chicken luncheon, 25 samples from each (breast, thigh muscles and liver) randomly collected from markets and analyzed by HPLC analysis. Findings revealed that the $9^{\text {th }}$ day after administration is the withdrawal day of ciprofloxacin residues. Freezing had a little effect on degradation of residues, boiling is the most efficient method in reduction of residues than roasting and frying. In survey, all samples of fresh, frozen chicken and chicken products were positive for ciprofloxacin residues and have levels exceed the MRL. Ciprofloxacin was widely used in broiler farms and found in nearly all samples in violative levels in chicken meat and its products. Withdrawal time of 9 days after treatment must be noticed and use of boiling in processing is more preferable.
\end{abstract}

Key words: Ciprofloxacin, chicken meat, HPLC, detection, freezing, boiling, roasting, frying.

\section{INTRODUCTION}

Ciprofloxacin is one of the second generation flouroquinolone antibiotics and has a broad spectrum effect against gram positive and gram negative bacteria and mycoplasma infection by inhibition of DNA gyrase enzyme that is essential for bacterial chromosome replication (Amjad et al., 2005, Xiao et al., 2014)). It is commonly used in human medicine, in animal production and in poultry farms for treatment and prophylaxis of bacterial infections. Also, it is used as growth promoters to stimulate growth and increase food intake and body gain (Donoghue, 2003). Its bioavailability and tissue distribution is excellent after oral administration (Papich, 1998). Ciprofloxacin is a primary metabolite of enrofloxacin in several animal species, including chicken and both enrofloxacin and ciprofloxacin are found in the muscle and tissue of chicken receiving enrofloxacin (Dimitrova et al., 2007).

Violative concentrations of ciprofloxacin residues in foods destined for human consumption can occurs due to the administration of ciprofloxacin to boiler without an adequate withdrawal time, use higher doses than prescribed, using for longer period than

Corresponding author: Dr. MOHAMED KARMI

E-mail address: karmy99@ yahoo.com

Present address: Department of Food Hygiene, Faculty of Veterinary Medicine, Aswan University, 81528 Aswan, Egypt recommended duration and using non-indicated route of administration (Mitchell et al., 1998). These drug residues causes several hazards to human health, such as formation of bacterial resistance, changes in intestinal microflora and hypersensitivity reactions (Fabrega et al., 2008). The use of ciprofloxacin doses lower than therapeutic dose in poultry industry is the main cause of acquisition of bacterial resistance (i.e. Campylobacter spp., Salmonella spp. and Escherichia coli) which adversely affects human medicine through reduction in the efficacy of such compounds in treating infections (WHO, 2011). Ciprofloxacin, even in low doses, strongly suppress facultative anaerobic human intestinal microflora which adversely affect digestion and vitamin synthesis (Cerngila and Kotarski, 1999). Several health risks such as antibiotic resistance, teratogenicity, carcinogenicity, hepatic and renal failure can threaten the consumers from consumption of chicken meat containing ciprofloxacin residues. Control of withdrawal times of antibiotics in poultry farms and post-mortem inspection of slaughtered carcasses for antibiotic residues can reduce the incidence of antibiotic residues and improve the safety of chicken meat (Karmi, 2014). The effect of cooking on ciprofloxacin residues should be studied to determine consumer's exposure to these drugs and any breakdown metabolites (Rose et al., 1999). Cooking temperature and duration greatly affecting the level of antibiotic residues in meat. Also, the chilling and freezing can lower the residue levels in stored meat (Haagsma, 1993). 
Many methods of high sensitivity and specificity were optimized and validated for detection and determination of different antibiotic residues in animal meat and poultry such as High Performance Liquid Chromatography (HPLC), Liquid Chromatography (LC), Liquid Chromatography-Mass Spectrometry (LC-MS), Thin Layer Chromatography (TLC), Enzyme-Linked Immunosorbent Assay (ELISA) and Microbiological Assays which used for qualitatively and quantitative determination of these antibiotic residues in food samples (Shareef et al., 2009). HPLC is the most preferable and most common method used in the determination of ciprofloxacin in poultry meat due to its higher sensitivity, higher specificity, short time and good performance (Gigosos et al., 2000, Garica-Ovando et al., 2004).

\section{MATERIALS AND METHODS}

\section{Samples}

This study consisted of two main parts; the first part is an experimental part consisted from 55 antibioticfree 35-days chickens that treated with therapeutic dose $(5 \mathrm{mg} / \mathrm{kg}$ body weight) in drinking water for three successive days to study the withdrawal time and the effect of freezing at $-20{ }^{\circ} \mathrm{C}$ for one month and heat treatment (boiling (at $100{ }^{\circ} \mathrm{C}$ for 9 minutes for liver and 24 minutes for muscles), roasting (at $200{ }^{\circ} \mathrm{C}$ for 25 minutes) and frying (in sunflower for 10 minutes)) on the drug residues. The second part is a survey consisted from 100 samples including fresh, frozen chickens, chicken burgers and chicken luncheon, 25 samples from each, were randomly collected from markets. Breast, thigh muscles and liver were taken from each chicken carcass for analysis.

\section{HPLC analysis}

Ciprofloxacin was extracted from tissues with dichloromethane (Sigma-Aldrich) and HPLC analysis of the samples was conducted using $\mathrm{C} 18$ column (250 $\mathrm{mm} \times 4.6 \mathrm{~mm}, 5 \mu \mathrm{m}$ ) and detected with photodiodearray detector at $280 \mathrm{~nm}$ wave length. The mobile phase consists of mixture of $0.1 \mathrm{M}$ orthophosphoric acid at $\mathrm{pH} 3.5$ and acetonitrile $(15: 85, \mathrm{v} / \mathrm{v})$.

\section{Calculation}

Standard curve of ciprofloxacin standard solutions (concentration versus peak area) was made and from measured peak area of test samples, ciprofloxacin concentration calculated by using linear equation as follows:

$$
\mathrm{y}=\mathrm{mx}+\mathrm{b}
$$

Where: y: peak area, x: ciprofloxacin concentration (ng/g), m: slope of curve, b: intercept of y

\section{RESULTS}

Results revealed that the $9^{\text {th }}$ day after administration is the withdrawal day of ciprofloxacin residues where the detected level of ciprofloxacin in all chicken tissues (breast, thigh and liver) was lower than the MRL and at day $11^{\text {th }}$ no residues were detected. Freezing of meat at $-20{ }^{\circ} \mathrm{C}$ for one month had a little effect on degradation of residues, the reduction percentage were $4.7 \%, 3.9 \%$ and $5.8 \%$ in breast, thigh and liver tissues, respectively. Boiling of tissues at $100{ }^{\circ} \mathrm{C}$ for 9 minutes for liver and 24 minutes for muscles have a dramatic effect where the reduction percentage of residues were $79.7 \%, 80.4 \%$ and $80.1 \%$ in breast, thigh and liver, respectively. Frying of chicken tissues in sunflower for 10 minutes showed reduction percentage, $53.5 \%, 57.8 \%$ and $43.6 \%$ in breast, thigh and liver, respectively. Roasting of meat in oven at $200{ }^{\circ} \mathrm{C}$ for 25 minutes for liver and 40 minutes for muscles causing reduction in residue levels in percentage of $41 \%, 39.9 \%$ and $32.4 \%$ in breast, thigh and liver, respectively. In survey study, about $76 \%, 80 \%, 88 \%, 92 \%$ and $80 \%$ of fresh chicken meat (breast and thigh), fresh liver, frozen chicken meat (breast and thigh), chicken burger and chicken luncheon were positive for the presence of ciprofloxacin residues, respectively. Comparing results of ciprofloxacin residues in chicken meat with EU MRLs revealed that about 64\%, 68\%, 76\%, 72\% $64 \%, 80 \%$ and $64 \%$ of fresh breast, fresh thigh, fresh liver, frozen breast, frozen thigh, burger and luncheon samples have residue levels above MRLs, respectively (Table 1).

Table 1 Incidence and number of ciprofloxacin residues in chicken meat and its products.

\begin{tabular}{ccccccc}
\hline \multirow{2}{*}{ Sample } & Number & \multicolumn{2}{c}{$\begin{array}{c}\text { Percentage of } \\
\text { positive samples }\end{array}$} & \multicolumn{2}{c}{$\begin{array}{c}\text { Percentage of } \\
\text { violative samples }\end{array}$} & \multirow{2}{*}{ EU MRLs (ng/g) } \\
\cline { 2 - 5 } & & No. & $\%$ & No. & $\%$ & \\
\hline Fresh breast & 25 & 19 & 76 & 16 & 64 & 100 \\
\hline Fresh thigh & 25 & 19 & 76 & 17 & 68 & 100 \\
\hline Fresh liver & 25 & 20 & 80 & 19 & 76 & 200 \\
\hline Frozen breast & 25 & 22 & 88 & 18 & 72 & 100 \\
\hline Frozen thigh & 25 & 22 & 88 & 16 & 64 & 100 \\
\hline Burger & 25 & 23 & 92 & 20 & 80 & 100 \\
\hline Luncheon & 25 & 20 & 80 & 16 & 64 & 100 \\
\hline
\end{tabular}

$\mathrm{N}$ : number of examined samples 
Table 2: Effect of freezing and heat treatments on the levels of ciprofloxacin residues in fresh chicken meat.

\begin{tabular}{llcccc}
\hline \multirow{2}{*}{ Sample } & & \multicolumn{4}{c}{ Reduction percentage of residues } \\
\cline { 3 - 6 } & & Freezing & Boiling & Roasting & Frying \\
\hline Fresh chicken $(\mathrm{n}=25)$ & Breast & 4.7 & 79.7 & 41 & 53.5 \\
\cline { 2 - 6 } & Thigh & 3.9 & 80.4 & 39.9 & 57.8 \\
\cline { 2 - 6 } & Liver & 5.8 & 80.1 & 32.4 & 43.6 \\
\hline
\end{tabular}

$\mathrm{n}$ : number of examined samples

\section{DISCUSSION}

In this study, results revealed that at the $9^{\text {th }}$ day after administration of last therapeutic dose of ciprofloxacin, the residue levels were below the EU MRLs and disappeared at day $11^{\text {th }}$. Also, higher ciprofloxacin residues were detected at zero day (6 hours after last dose) in breast, thigh muscles and in liver, the liver reached highest levels and depleted slower than muscles (EMEA, 2002, Ellis, 2004). It is observed that residue concentrations in breast muscles were higher than those in thigh muscles which agreed with similar findings (Reyes-Herrera et al., 2005, Abou Elnile, 2006, Alestig, 1990). The withdrawal time is the period of time required after completion of treatment needed for tissues concentrations of the drug and/or its metabolites to deplete to less than the established MRLs, so that to deliver safe food for human consumption, the withdrawal time of drugs must be observed and the inappropriate withdrawal period is the most common cause for presence of illegal drug residues in meat that have risk on human health (Kukanich et al., 2005, Paige et al., 1999). Concerning the effect of freezing on reduction of ciprofloxacin residues showed that freezing has a very little effect and these findings in agreement with others who stated that freezing may act as a factor in reduction of antibiotic residues in frozen samples (Mahmoud and Mohsen, 2008, Haagsma, 1993, Eissa et al., 1998). The antibiotic residues have a varying degrees of stability during cooking, therefore cooking influences the level of risk pose by such residues, also, study the effect of different methods of processing on residue levels become needed to accurately determine the risk for consumer (Moats, 1999, Rose et al., 1999). Boiling is the most efficient method in reduction of residues then followed by frying and roasting. The reduction rate were up to $80 \%, 57 \%$ and $41 \%$ for boiling, frying and roasting, respectively. Cooking processes cannot remove the total amounts of ciprofloxacin residues but it can only decrease its amounts. Also, most of the residues in boiling process were excreted from tissues into cooking fluid; so that discarding any juices which come from the edible cooked tissues may be reduce exposure to antibiotic residues (Javadi et al., 2011, Fathy et al., 2015, Heshmati, 2015, Javadi, 2011). Other authors have another opinion who stated that cooking procedures do not reduce the enrofloxacin and its metabolite ciprofloxacin, as this residue retained its stability during heating, so that higher reduction rate by boiling while lower rate in case of water loss processing such as roasting and grilling (Lolo et al., 2006, Botsoglou and Fletouris, 2001, Rose et al., 1999, Steffenak et al., 1994). In survey study, results showed that high percentages of chicken meat and its products were positive for ciprofloxacin residues (76-92\%) and also, higher rates of them exceeded the established EU MRLs (64$80 \%)$. It is noticed, also, that chicken products (burger and luncheon) were higher than carcasses and frozen samples were higher than fresh and liver samples were higher than muscles. Increased demand for chicken meat, higher prices of red meats, need for more meat production and rapid breeding forces people to use more antibiotics for growth stimulation and weight promotion (Paryad and Mahmoudi, 2008), extensive non-therapeutic use of antibiotics and lack of adequate control of administration and withdrawal times increase the risk of accumulation in chicken meat and its products (Lemus et al., 2008). Presence of antibiotic residues and their metabolites in chicken meat may cause several adverse effects for human such as direct toxicity, developing resistant bacteria, allergies, hypersensitivity reactions, harms intestinal microflora, affect digestion and vitamins synthesis, even in very low doses in contaminated foods (Kirbis, 2007, Myllyniemi, 2004, javadi, 2011), therefore many food agencies established maximum limits of drug residues (MRLs) which are the maximum amount of residues that could legally permitted to be in the food product without causing adverse effects to the consumers (Reyes-Herrera et al., 2005). Veterinary drug residue concentrations in meat depend on various factors such as drug dosage, animal species, age, feeding, healthy status, poor management, extra-label drug use, withdrawal time and route of administration (Kaneene and Miller, 1997, Codex Alimentarius Commission, 2001).

\section{CONCLUSION}

Ciprofloxacin residues were very common in all chicken meat and chicken products and in violative levels higher than MRLs; this finding may be due to common use of such antibiotic in poultry farms either for treatment or as growth enhancer. Withdrawal time of 9-11 days after treatment must be observed and use 
of boiling in processing is more preferable. Regular and routine monitoring of chicken meat and products for ciprofloxacin residue should be conducted.

\section{AUTHORS' CONTRIBUTIONS}

Author performs collection, preparation, processing, and analysis of samples, data acquisition, writing, preparation and revision of manuscript.

\section{ACKNOWLEDGEMENTS}

I thank Faculty of Veterinary Medicine, Aswan University for Financial support

\section{REFERENCES}

Aboul Elnile, M.O. (2006): Effect of boiling and freezing on ciprofloxacin residues in chicken tissues. Assiut Veterinary Medicine Journal, 52 (110), 111-120.

Alestig, K. (1990): Pharmacokinetics of oral quinolones (norfloxacin, ciprofloxacin and ofloxacin). Scandinavian Journal of Infectious Disease, 68, 19-22.

Amjad, H.; Iqbal, J. and Naeem, M. (2005): Analysis of some residual antibiotics in muscle, kidney and liver samples of broiler chicken by various methods. Proceeding of Pakistan Academy of Science, 42 (4), 223-231.

Botsoglou, N.A. and Fletouris, D.J. (2001): Stability of residues during food processing. Marcel Dekker, Inc., New York.

Cerniglia, C.E. and Kotarski, S. (1999): Evaluation of veterinary drug residues in food for their potential to affect human intestinal microflora. Regulatory Toxicology and Pharmacology, 29, 238-261.

Codex Alimentarius Commission (2001): Committee on residues of veterinary drugs in foods, document control of veterinary drug residues in milk and milk products. Joint food and agriculture organization of the United Nations world health organization food standards programme, Rome.

Dimitrova, D.J.; Lashev, L.D.; Yanev, S.G. and Pandova, B. (2007): Pharmacokinetics of enrofloxacin in turkey. Research in Veterinary Science, 82, 392.

Donoghue, D.J. (2003): Antibiotic residues in poultry tissues and eggs: Human health concern. Poultry Science, 82, 618-621.

Eissa, I.A.M.; Mona, S.M.A. and Ahmed, E.E.K. (1998): Studies on residues and effect of antibiotics in treated Cat fish (Clarias lazera) experimentally and in Ismailia Youth Cultivated Fish project. Suez Canal Veterinary Medicine Journal, 1 (1), 199-208.

Ellis, R. (2004): U.S. FDA Regulatory approach for control of residues of veterinary drugs. Joint
FAO WHO technical workshop on residues of veterinary drugs without ADI MRL. Food and Agriculture Organization and World Health Organization, Geneva.

EMEA (The European Agency for the Evaluation of Medicinal Products) (2002): Enrofloxacin, extension to all food producing species, Summary report (5), EMEA/MRL / 820 / 02FINAL.

Fabrega, A.; Sanchez-Cespedes, J.; Soto, S. and Vila, $J$. (2008): Quinolone resistance in the food chain. International Journal of Antimicrobial Agents, 31, 307-315.

Fathy, F.M.; Ahmed, A.M. and Moursi, M.K. (2015): Effect of cooking methods on antibiotic residues in broiler chicken. Second Conference of Food Safety, Suez Canal University, Faculty of Veterinary Medicine, 1, 76-81.

García-Ovando, H.G.; Gorla, N.; Weyers, A.; Ugnia, L. and Magnoli, A. (2004): Simultaneous quantification of ciprofloxacin, enrofloxacin and balofloxacin in broiler chicken muscle. Journal of Archivos de MedicinaVeterinaria, XXXVI (1), 93-98.

Gigosos, P.G.; Revesado, P.R.; Cadahia, O.; Fente, C.A.; Vazquez, B.I.; Franco, C.M. and Cepeda, A. (2000): Determination of quinolones in animal tissues and eggs by HPLC with photodiode-array detection. Journal of Chromatography A, 871, 31-36.

Haagsma, N. (1993): Stability of veterinary drug residues during storage preparation and processing of the Euro residue conference veldhoven. The Netherlands, 1, 9-41.

Heshmati, A. (2015): Impact of cooking procedures on antibacterial drug residues in foods: A Review. Journal of Food Quality and Hazards Control, 2, 33-37.

Javadi, A. (2011): Effect of roasting, boiling and microwaving cooking method on Doxycline residues in edible tissues of poultry by microbial method. African Journal of Pharmacy Pharmacology, 5(8), 1034-1037.

Javadi, A.; Mirzaie, H. and Khatibi, S.A. (2011): Effect of roasting, boiling and microwaving cooking methods on enrofloxacin residues in edible tissues of broiler. African Journal of Pharmacy Pharmacology, 5(2), 214-218.

Kaneene, J.B. and Miller, R. (1997): Problems associated with drug residues in beef from feeds and therapy. Review of Scientific Technology Office of International Epizootics, 16, 694-708.

Karmi, M. (2014): Detection and presumptive identification of antibiotic residues in poultry meat by using FPT. Global Journal of Pharmacology, 8 (2), 160-165.

Kirbis, A. (2007): Microbiological screening method for detection of aminoglycosides, $\beta$-lactames, macrolides, tetracyclines and quinolones in 
meat samples. Slovenian Veterinary Research, $44(1 / 2), 11-18$.

KuKanich, B.; Gehring, R.; Webb, A.; Craigmill, A. and Riviere, J. (2005): Effect of formulation and route of administration on tissue residues and withdrawal times. Journal of the American Veterinary Medical Association, 227, 15741577.

Lemus, J.A.; Blanco, G.; Grande, J.; Arroyo, B.; Garcia-Montijano, $M$. and Martinez, $F$. (2008): Antibiotics threaten wildlife: circulating quinolone residues and disease in avian scavengers. PLOS ONE, 3 (1), 1-6.

Lolo, M.; Pedreira, S.; Miranda, J. M.; Vázquez, B.I.; Franco, C. M.; Cepeda, A. and Fente, C. (2006): Effect of cooking on Enrofloxacin residues in chicken tissue. Food Additives and Contaminant: Part A, 23 (10), 988-993.

Mahmoud, A.A. and Mohsen, A.M. (2008): Incidence of some antibiotic residues in broiler meat at North Sinai Governorate. Zagazig Veterinary Journal, 36(5), 129-133.

Mitchell, J.M.; Griffiths, M.W.; McEwens, S.A.; McNab, W.B. and Iee, L. (1998): Antimicrobial drug residues in milk and meat causes, concerns prevalence, regulations, test and test performance. Journal of food protection, 61 (6), 742- 756.

Moats, W.A. (1999): The effect of processing on veterinary residues in foods. Advances in Experimental Medicine and Biology, 459, 233-241.

Myllyniemi, A.L. (2004): Development of microbiological methods for the detection and identification of antimicrobial residues in meat. National Veterinary and Food Research Institute, Helsinki, Finland.

Paige, J.C.; Chaudry, M.H. and Pell, F.M. (1999): Federal surveillance of veterinary drugs and chemical residues (with recent data).
Veterinary Clinics of Nourth America: Food Animal Practice, 15, 45-46.

Papich, M.G. (1998): Antibacterial drug therapy. Focus on new drugs. Veterinary Clinics of North America: Small Animal Practice, 28, 215-231.

Paryad, A. and Mahmoudi, M. (2008): Effect of different levels of supplemental yeast (saccharomyces cerevisiae) on performance, blood constituents and carcass characteristics of broiler chicks. African Journal of Agricultural Research, 3 (12), 835-842.

Reyes-Herrera, I.; Schneider, M.J.; Cole, K.; Farnell, M.B.; Blore, P.J. and Donoghue, D.J. (2005): Concentrations of antibiotic residues vary between different edible muscle tissues in poultry. Journal of Food Protection, 68 (10), 2217-2219.

Rose, M.D.; Bygrave, J. and Sharman, M. (1999): Effect of cooking on veterinary drug residues in food. Analyst, 124 (3), 289-294.

Shareef, A.M.; Jamel, Z.T. and Yonis, K.M. (2009): Detection of antibiotic residues in stored poultry products. Iraqi Journal of Veterinary Sciences, 23 (3), 45-48.

Steffenak, I.; Hormazabal, V. and Yndestad, M. (1994): Effect of cooking on residues of the quinolones, Oxolinic acid and Flumequine in fish. Acta Veterinaria Scandinavica, 35, 299301.

WHO (2011): Reduce use of antimicrobials in foodproducing animals. World Health Day 2011, Policy package to combat antimicrobial drug resistance.

Xiao, R.; He, Z.; Diaz-Rivera, D.; Pee, G.Y. and Weavers, L.K. (2014): Sonochemical degradation of ciprofloxacin and ibuprofen in the presence of matrix organic compounds. Ultrasonic Sonochemistry, 21(1), 428-435.

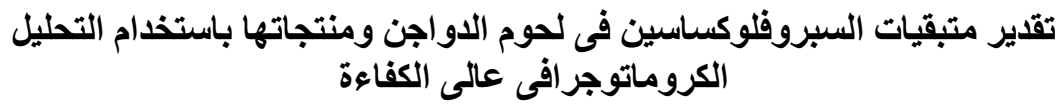

Email:karmy99@yahoo.com $\quad$ Assiut University web-site: www.aun.edu.eg

تتكون هذه الدراسة من جزئين أساسيين: الجزء الأول تجريبى وتتكون من

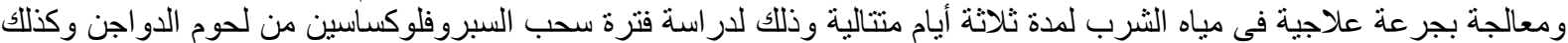

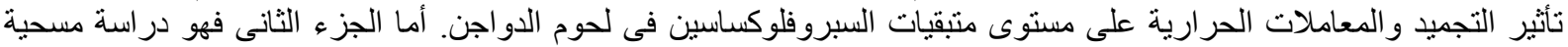

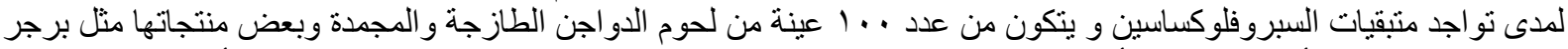

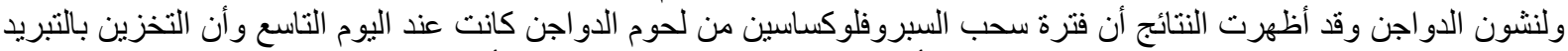

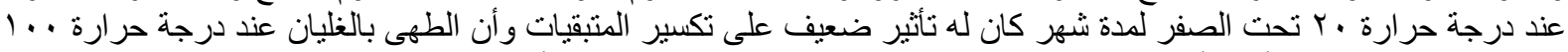

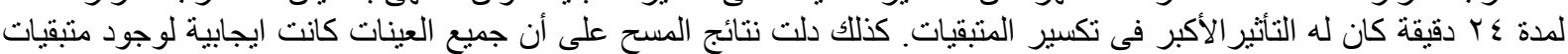

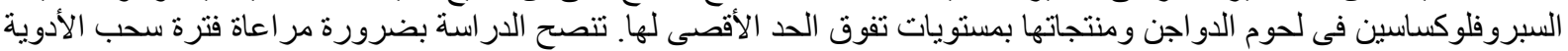

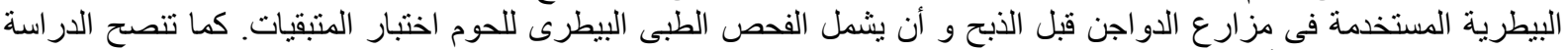

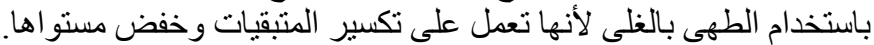

